\title{
Effect of steam addition on gas turbine combustor design
}

\section{and performance}

\section{Rui Xue $^{\mathrm{a}, \mathrm{b}}$, Chunbo Hu${ }^{\mathrm{a}}$, Vishal Sethi ${ }^{\mathrm{b}}$, Theoklis Nikolaidis ${ }^{\mathrm{b}}$, Pericle Pilidis ${ }^{\mathrm{b}}$}

\begin{abstract}
Adding steam influences the combustion process inside the combustor, which should be taken into account during combustor design. The design of combustor has long been the most challenging process. This study integrated the gas turbine performance with the combustor design, and formulated a detailed procedure for single annular combustors with steam addition consideration in particular. To accomplish this, a computer code has been developed based on the design procedures. The design model could provide the combustor geometry and the combustor performance. The inlet parameters for combustor design are obtained and validated through the calculation of gas turbine engine performance provided by our own home code. The model predictions are compared with operational and configuration data from two real engines and show reasonably good accuracy. The influence of steam addition on combustor design is investigated and results showed the variation of geometrical size is highest for components where intense combustion takes place while the design is almost kept the same for components where only pure flow exists. After conforming the feasibility of the combustor design code, we investigated the effects of steam addition on combustor performance. It revealed that steam injection is an effective way to reduce the temperature in the burner while other performance like the total pressure loss would be slightly deteriorated.
\end{abstract}

Keywords

Gas turbine combustor; steam addition; preliminary combustor design; performance 


\section{Introduction}

At present, global demands for transportation and energy are met through the combustion of fossil fuels such as petroleum-based liquid fuels. As a result, emissions are an increasingly important consideration in the design of aircraft engines. Among the different kinds of emissions, nitrogen oxides are a primary air pollutant linked to photochemical smog, acid rain, and tropospheric ozone at ground-level, such as in the case aircraft takeoff in airports. With increasing concerns about the effects of aircraft emissions on the local air quality in the vicinity of airports, it has become necessary for engine manufacturers to develop more environmentally friendly technologies that could be efficiently applied to the reduction of combustion emissions.

Among the emission reduction technologies that have been developed for aircraft engines, steam or water injection methods are becoming popular for NOx emission reduction at takeoff conditions due to the low technology risk and cost. Several studies have been undertaken to understand the influence of steam addition on fuel combustion and NOx emissions [1-5]. A preliminary aircraft performance investigation including system design, engine performance, maintenance, and the cost implications of using this technology in aircrafts at takeoff was carried out on at the NASA Glenn Research Center [6, 7]. Unlike old-style water-injection methods, this approach was found to be capable of reducing the specific fuel consumption (SFC), NOx emissions, and turbine inlet temperatures. Furthermore, an experimental and numerical study conducted by Benini et al. [8] showed that steam injection led to a reduction in the NO formation in a proprietary turbojet chamber. Applying steam/water-injection schemes in future aircraft and power plants could effectively reduce pollution and operating costs as well as improve performance [6-13]. Zhang et al. integrated the partial oxidation gas turbine (POGT) with a steam injected gas turbine cycle (STIG) and investigated the overall performance of this cycle and the influences of key variables [9]. Calculation results showed that the combustor outlet temperature and the compressor 
pressure ratio of the bottoming gas turbine cycle, and the temperature of partial oxidation affected the efficiency and specific work output of this cycle obviously. Compared to other simple cycles, the efficiency of this cycle was two percentage points higher, the oxygen concentration decreased, and the cooling flow rate increased. The investigation of steam injected gas turbine cycle with steam conducted by Elwekeel and Abdala [13] showed the total exergy destruction rate decreased with saturated steam coolant temperature and the network and plant efficiency increased at a higher saturated steam coolant temperature.

Generally, for all the current emission-prediction models, from the simple correlation-based model to complicated high-fidelity CFD simulation, the determination of the basic combustor dimensions is a prerequisite. Combustor design, which includes many disciplines such as aerodynamics, materials science, combustion, mechanical design, and production engineering, is assumed one of the most challenging aspects of gas turbine engine development [14]. Over many decades, many experimental data and analysis results have been gathered as a result of scientific and industrial research across the world. However, the empirical and analytical methods are still the most widely used tools for current gas turbine combustor design. Mellor [15] and Lefebvre [16] established an extensive list of empirical and analytical tools for application to combustor design. They illustrated the assumptions behind the design equations as well as their range of validity. Mohammad [17] and Mattingly [18] collected these methods to devise a combustor design procedure. In modern gas turbine combustors, the compressor outlet temperature is always higher than $800 \mathrm{~K}$ (the critical temperature of water is $647.5 \mathrm{~K}$ ). Thus, the injected water would be vaporized in the front of the combustor when water is injected into the low-pressure compressors. This would surely lead to the physical and chemical processes becoming more complicated in the combustor. Therefore, this should be considered during the preliminary design stage to drive down development costs and the business risk associated with the engine design. 
This study set out to investigate the effects of steam addition on combustor design and performance at the conceptual design stage. First, a preliminary design procedure for annular gas turbine combustors was established. Two representative annular combustors were used to validate this model, based on the required design requirements and operating conditions at the design point. This design program will also enable the designer to fine-tune several critical parameters and check their impact on the combustor's size and performance in a timely manner. Next, the operating conditions were fixed and the combustor was redesigned while taking steam addition technology into consideration. Finally, the combustor performance with steam injection was calculated and compared with the results obtained under dry conditions.

\section{Design methodology}

In this combustor design model, we split the combustor into a number of elements/components. Here, “elements" do not simply refer to actual components. Some of the elements are actual components (e.g. the primary zone and the swirler) while others are used for calculating the necessary gas and flow parameters. Each element contains theoretical, analytical, and experimental correlations for calculating the corresponding gas and steam properties, flow distribution, cooling flow control, steam addition modification, or component dimensions/ performance.

\subsection{Gas property model}

The calculation of the flame temperature and gas properties is pivotal to flow field simulation. Generally, the most commonly used procedure for temperature and composition computation is based on the minimization of the Gibbs free energy technique. However, at the preliminary design stage, the Gibbs free energy method involves long iteration procedures resulting in time-consuming and expensive calculations. Therefore, a correlation technique, developed by Gülder $[23,24]$ is adopted to predict the 
adiabatic flame temperature and gas properties of fuel/air combustion. Detailed definitions or the values of the parameters in Eq. (1) and (2) are shown in Appendix 1.

$$
\begin{aligned}
& T_{a d}=A \sigma^{\alpha} \cdot \exp \left[\beta(\sigma+\lambda)^{2}\right] \cdot \pi^{x} \theta^{y} \psi^{z} \\
& \Omega_{k}=A S^{\alpha} \cdot \exp \left[\beta(\sigma+\lambda)^{2}\right] \cdot \pi^{x} \theta^{y} \psi^{z}
\end{aligned}
$$

\subsection{Geometry model}

Geometry calculation is conducted for the various parts of the design model. From an overview prospective, the combustor may be tilted from the diffuser inlet to the transition duct exit. This tilt angle between the combustor "mean line" and engine axis is assumed to be constant and varies until the exit mean radius matches the high-pressure turbine mean radius. The combustor geometry model consists of a diffuser, swirler, injector, primary zone, secondary zone, and dilution zone. The overall combustor layout is shown in Fig. 1.

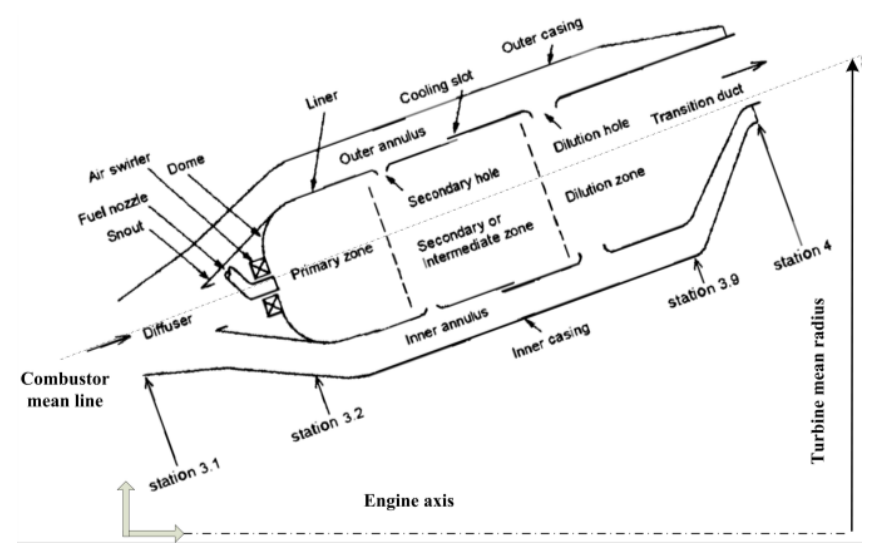

Fig.1. Gas turbine combustor layout [18].

\subsubsection{Diffuser}

The diffuser is the first component in a combustor system. The primary task of the diffuser is to slow down the inlet flow Mach number to a level at which the flame in the burner is stable. There are different types of diffusers in applications, such as the conventional flat-wall diffuser, the dump diffuser, and the combined flat-wall + dump diffuser. In the diffuser design, the diffusion process is assumed to be 
adiabatic but not isentropic, while the pressure loss efficiency is a key factor for determining the final configuration. Previous research [11] has shown that, for simple configurations like the flat-wall diffuser, this factor is related to the diffuser half-angle, and empirical relationships have been established to compute this. As the required total area ratio exceeds the maximum ratio of the flat-wall diffuser, an additional dump duct should be added to form a combined diffuser. Then, the total diffusion efficiency is computed as shown in Eq. (3) [18]. Furthermore, to prevent flow separation, splitters, which divide the diffuser duct into multiple passages, could be installed. The objective of diffuser design is to achieve the desired burner inlet Mach number with minimum losses for given constraints.

$$
\eta_{t o t}=\frac{\eta_{D m} A R^{2}\left(1-\left[A_{1} / A_{m}\right]^{2}\right)+2\left(A R\left[A_{1} / A_{m}\right]-1\right)}{\left(A R^{2}-1\right)}
$$

\subsubsection{Design reference parameter and air distribution.}

After achieving the required velocity reduction in the diffuser, the air flows into the burner where it mixes and reacts with the injected fuel. Before starting to design the specific combustion zones, some assumptions and important reference parameters should be illustrated first. Throughout the entire burner design process, the total pressure, as well as the liner and casing cross-sectional areas in different zones is assumed to be constant. A transition part is added at the end of the burner to reduce the outlet area and thus choke the outflow. Given these hypotheses, a constant velocity is obtained for every jet flowing from the casing into the liner. The pressure-loss coefficient, $\Delta P_{t} / q_{r}$, which is defined as the ratio of the total pressure loss to the diffuser outlet dynamic pressure, is an important reference parameter during the burner design process. This parameter can be assumed to be constant provided the combustor dimensions are fixed.

$$
\left(\frac{A_{\text {Liner }}}{A_{\text {Casing }}}\right)_{\text {optimum }}=1-\left(\frac{\dot{m}_{P Z}}{\dot{m}_{t o t}}\right)^{3 / 2}\left(\frac{\Delta P_{t}}{q_{r}}\right)^{-1 / 3}
$$


The amount of airflow sent to the primary zone depends on the required combustion equivalence ratio. By knowing the air mass fraction of the primary zone, another important reference parameter, the linercasing area ratio can be determined (Eq. (4)). Furthermore, based on the flame temperature as well as the liner material and the cooling method, the required cooling flow to keep the liner wall below the material's temperature limit can be determined. For the secondary zone, the amount of injected air is computed such that the total temperature is similar to that of the primary zone when no cooling flow is taken into account. The remaining the air flow passes into the dilution zone through the jet holes.

\subsubsection{Swirler and primary zone}

Air is injected into the primary zone through a component called a "swirler". For actual applications, to produce a recirculation region to maintain the stability of the flame, the swirler number, which is defined in Eq. (5), should be larger than 0.6 [16]. In addition, the height of the swirler duct is obtained by calculating the area using Eq. (6) and (7). In the design process, if the hub radius and swirler parameter $K_{S W}$ are known, then the swirler blade angle and number of fuel nozzles can be iterated until the swirler dimensions can fit into the liner dome, while some other extra design requirements are also satisfied.

$$
\begin{aligned}
& S W=\frac{2}{3} \operatorname{Tan}\left(\alpha_{S W}\right) \frac{1-\left(\frac{r_{h u b}}{r_{t i p}}\right)^{3}}{1-\left(\frac{r_{h u b}}{r_{t i p}}\right)^{2}} \\
& A_{S W}=\sqrt{\frac{K_{S W}}{\operatorname{Cos}\left(\alpha_{S W}\right)^{2}} \frac{1}{\frac{2 \rho_{S W} \Delta P_{S W}}{\dot{m}_{S W}}+\left(\frac{1}{A_{\text {linear }}}\right)^{2}}} \\
& r_{\text {tip }}=\sqrt{\frac{A_{S W}}{\pi}+r_{h u b}^{2}}
\end{aligned}
$$

\subsubsection{Secondary and dilution zones.}


The flow then enters the secondary and dilution zones through the air jet holes. The diameter of the holes is computed by specifying the penetration ratio of the dilution jets in the secondary and dilution zones in Eq. (8) and (9) [18]. The corresponding dynamic pressure ratios in these two equations are calculated based on the laws of conservation and the Boussinesq assumption. The length of both the secondary zone and the dilution zone are determined by specifying the height-to-length ratios, which are obtained according to the combustor design requirements and the engineering ranges.

$$
\begin{gathered}
\frac{Y_{\max }}{d_{j}}=1.15 \sqrt{\frac{q_{\text {jet }}}{q_{\text {liner }}}\left(1-\frac{q_{\text {annular }}}{q_{\text {jet }}}\right)} \\
d_{\text {orifice }}=\frac{1}{\sqrt{c_{d}}}\left(\frac{Y_{\max }}{H_{\text {liner }}}\right)\left(\frac{Y_{\max }}{d_{j}}\right)^{-1} H_{\text {liner }}
\end{gathered}
$$

\section{Case study and validation}

This section addresses the testing and validation of the proposed preliminary design methodology. Due to more open data on combustor parameters being available in the public domain, two typical turbofan engines which are similar to the CFM56 series of engines [21] as well as the NASA Energy Efficient Engine (E3) [22, 23] respectively, are established under the environment of the in-house software, TurboMatch $[24,25]$. Therefore, the combustor design operating parameters such as the total temperature and pressure, and fuel /air flow rates can be obtained.

The takeoff condition is chosen as the design point. Other conditions are defined by the Federal Aviation Administration (FAA) requirements: 1) Climb-out: the period during which the aircraft leaves the mixing zone (85\% power setting); 2) Approach: the period during which the aircraft enters the mixing zone and during which it lands (30\% power setting); and 3) Idle: the period while the aircraft is taxiing before takeoff and after landing (7\% power setting). These conditions are used as the off-design 
calculation points. The validation and detailed engine performance data for these two engine models are not shown here for brevity. The inlet operating values for these two model combustors under the design condition are as shown in Table 1.

Table 1. Combustor inlet operating values at design condition

\begin{tabular}{lll}
\hline Parameters & CFM56 model & E3 model \\
\hline Inlet total pressure (atm) & 28.5 & 30.0 \\
Inlet total temperature (K) & 800.5 & 815.0 \\
Fuel flow rate (kg/s) & 1.30 & 1.35 \\
Air flow rate (kg/s) & 43.92 & 55.2 \\
\hline
\end{tabular}

Table 2. Combustor preliminary design results

\begin{tabular}{llcc|ccc}
\hline & \multicolumn{2}{c}{ CFM56 model } & & \multicolumn{2}{c}{ E3 model } \\
& Model & Data[21] & \% Deviation & Model & Data[23] & \% Deviation \\
\hline Overall dimension & & & & & & \\
\hline Diffuser length (m) & 0.123 & 0.119 & 2.56 & 0.085 & 0.099 & -13.40 \\
Primary zone length (m) & 0.051 & 0.053 & -3.98 & 0.035 & 0.034 & 1.48 \\
Secondary zone length (m) & 0.059 & 0.060 & -0.85 & 0.041 & 0.040 & 2.56 \\
Dilution zone length (m) & 0.066 & 0.065 & 1.57 & 0.054 & 0.053 & 0.48 \\
Linear height (m) & 0.084 & 0.086 & -2.06 & 0.074 & 0.076 & -2.67 \\
Casing height (m) & 0.106 & 0.012 & -11.08 & 0.097 & 0.119 & -18.58 \\
\hline Jet holes & & & & & & \\
\hline Fuel nozzle number (-) & 20 & 20 & 0 & 19 & 20 & -5.00 \\
Secondary zone jet hole number (-) & 79 & 80 & -1.25 & 81 & 80 & 1.25 \\
Dilution zone jet hole number (-) & 120 & 120 & 0 & 120 & 120 & 0 \\
\hline
\end{tabular}

Table 2 shows the calculated results obtained with the design model, compared with the open data [21-23]. There is good agreement between the model results and the open data. The discrepancy for most of the design parameters is within $\pm 5 \%$ but a noticeable discrepancy exists in the casing height of the model combustors. The reason for this is that the casing height is assumed to be equal to the diffuser outlet height for which the value is calculated according to the final total area ratio. This area ratio is a function of both the flow property and the pressure loss coefficient, as shown in Eq. (3). This equation requires the flat-wall diffuser pressure loss efficient and the flat-wall diffuser outlet area, which are computed based on the experimental empirical correlations. At present, to the best of our knowledge, 
most proposed diffuser design models are based on results obtained with specific diffusers. Therefore, the inaccuracy of the diffusion efficiency models employed in this paper is the reason for this deviation. More generic diffuser efficiency models should be investigated in the future.

In addition, to reduce the overall combustor length and avoid flow separation, two splitters are inserted into the diffuser duct of the combustor, in much the same way as in the E3 engine. Thus, unlike the single duct in the diffuser model of the CFM engine, there are three passages in the E3 diffuser model. The diffuser design model presented in this paper enables the calculation of the parameters for single duct diffusers. It should be noted that no other models capable of performing multiple duct diffuser calculations appear to have been published in the literature. Accordingly, the calculation discrepancy for the E3 model diffuser length is greater than that for the CFM diffuser model. The differences for other parameters such as the burner zone length and number of air jet holes is small. In general, based on these results, we could conclude that the method in this investigation demonstrates acceptable prediction capabilities in the preliminary design stage and could therefore be adopted for the steam addition study described in the next section.

\section{Steam addition effect on combustor design}

It is known that steam has a high heat capacity, which is nearly double that of dry air. Thus, the property of the inlet gas mixture would be altered considerably when steam is injected in front of the diffuser. In addition, due to its physical and chemical properties, steam could also effectively reduce the flame temperature. The physical effect of steam addition is easy to understand while its chemical influence is complicated. Research into chemical mechanisms [5] has shown that steam exhibits a high chaperon efficiency (a parameter used to quantify the chemical enhancement effects of a third-body) in elementary reactions for hydrocarbon fuel reactions. Thus, the most important terminating reaction $\mathrm{H}+$ $\mathrm{O}_{2}+\mathrm{M}=\mathrm{HO}_{2}+\mathrm{M}$, by which a relatively inactive product $\mathrm{HO}_{2}$ product could be obtained by consuming the active $\mathrm{H}$ atom, would be enhanced with the addition of steam. This could reduce the total heat release 
to some extent. By using data generated by CEA, a correlation was developed to determine the flame temperature as a function of the water to fuel mass ratio in Eq. (10) [26]:

$$
\begin{aligned}
T_{\text {flame,wet }} & =T_{\text {flame }, d r y} \cdot(1+\lambda)^{-0.151} \\
C_{p, \text { mix }} & =\sum w_{i} C_{p, i}
\end{aligned}
$$

In general, the assumption of an ideal gas for the gas mixture is reasonable under the normal gas turbine combustor operating conditions. Therefore, the total heat capacity of the mixture is computed as given by Eq. (11). Details of the steam heat capacity model are given in Reference [27]. Then, other parameters such as the gas constant and the isentropic coefficient of the mixture could be obtained based on their relationship with the heat capacity.

Four different steam mass fractions (steam/ (steam + dry air)): 5\%, 10\%, 15\%, and 20\%, which involve the maximum steam content in an application, are selected to investigate the effect of the steam addition on the combustor design in this section. To enable a comparison with the results of the previous reference design, the operating conditions were not altered and the same total gas mixture flow rate was also used. Fig. 2 shows the relative change in combustor design parameters compared to the dry air reference parameters when different amounts of steam are added.
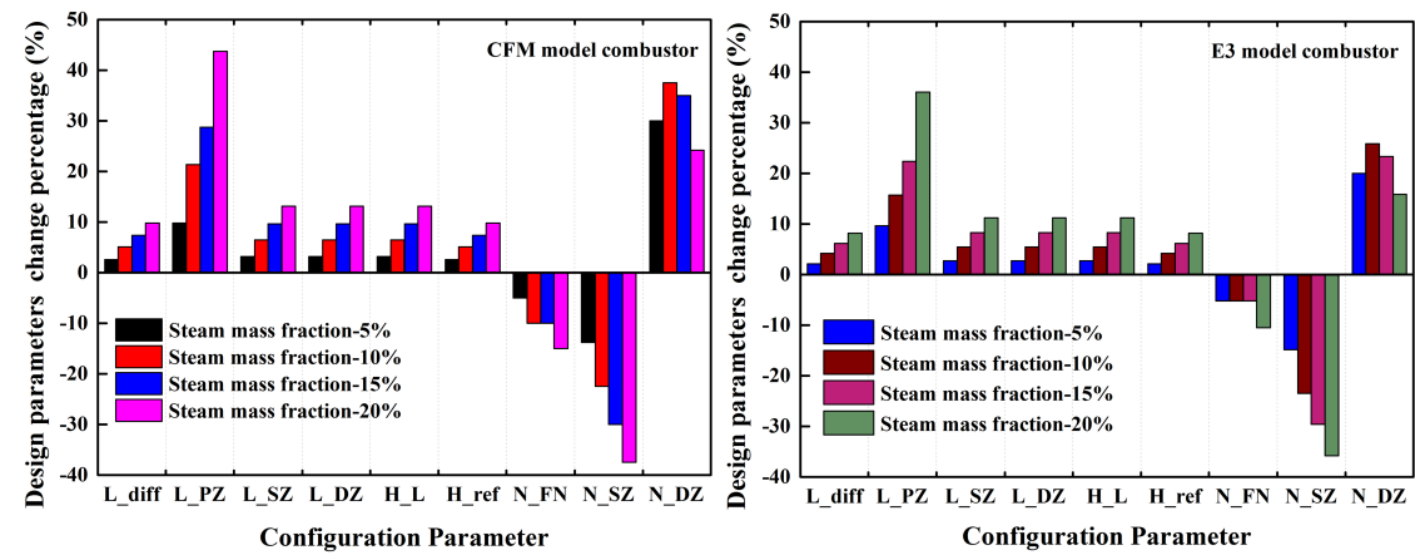
Fig. 2. Combustor design parameters change percent for the two model combustors at different steam mass fractions (steam/ (steam + dry air)).

With either of these two annular model combustors, the results show that the relative change in the design parameters of the diffuser is smallest, relative to that for the other components. As there is no combustion, the diffuser design is mainly determined by the inlet gas properties and its type. In addition, since the operating conditions are fixed in this study, the influence of steam addition on the diffuser design is primarily through changing the gas properties like the gas constant and the isentropic coefficient. Take the CFM engine model combustor as an example. When the steam mass fraction reaches $20 \%$, the inlet mixture constant $R$ increases from $287.2 \mathrm{~J} /(\mathrm{mol} \cdot \mathrm{K})$ to $322.2 \mathrm{~J} /(\mathrm{mol} \cdot \mathrm{K})$, while the isentropic coefficient $\gamma$ is reduced slightly from 1.35 to 1.32 . Based on the flow area computation Eq. (12), the dimension of the diffuser should be increased if the burner inlet Mach number and flow rate to be held constant in this situation.

$$
A=\frac{\dot{m} \sqrt{T_{t o t}}}{P_{t o t} w f f} \quad w f f=\sqrt{\frac{\gamma}{R}} M\left(1+\frac{\gamma-1}{2} M^{2}\right)^{-\frac{\gamma+1}{2(\gamma-1)}}
$$

As the steam mass fraction increases, both the length and the height are increased for those zones in the burner, especially the primary zone. The equivalence ratio of the primary zone is kept the constant. Therefore, the total flow rate in the primary zone will be increased, which directly results in the height of the primary zone increasing. Furthermore, the length of the primary zone is obtained by calculating the swirler dimension (blade tip diameter $r_{t i p}$ ) and its swirl number. As shown in Eq. (5), the swirler area is influenced by the diffuser outlet gas density. Based on the ideal gas state equation, when steam is added, the mixture gas constant should be reduced. This could cause the mixture density to become smaller at the diffuser outlet. Therefore, by taking this density value into the swirler model, both the swirler tip diameter and swirl number are increased, which jointly result in the primary zone becoming longer. For other 
zones such as the secondary and dilution zones, as no general and accurate models have so far been developed to calculate the zone length, the height to length ratios are used to compute the length of these two zones in this study. Therefore, the trends of the length change are in line with the change in their height for these two zones.

In addition, another obvious change is the number of air jet holes. In the secondary zone, as the steam mass fraction increases, the number of jet holes decreases, with the rate of decrease being proportional to the injected steam mass fraction. For the dilution zone, however, the number of jet holes is increased with steam addition when the steam mass fraction is less than $10 \%$. After that, adding more steam would lead to the number of holes being reduced and the reduction rate being greater than the rate of increase when a small amount of steam is injected. From Eq. (8) and (9), it can be seen that the number of jet holes is influenced by both the flow state and the flame temperature in the burner, which means that the number of jet holes is determined by the coupled physical and chemical processes in the combustor. Therefore, unlike the change in the diffuser dimensions that is determined only by thermodynamic process, the variation in the number of jet holes is a non-monotonic transition.

When considering the number of fuel nozzles, these two model combustors exhibit different characteristics. For the CFM engine model combustor, the number of fuel nozzles first decreased when the steam mass fraction is less than $10 \%$. Subsequently, adding more steam would not change the fuel nozzle number until the steam content is quite high (a steam mass fraction of 15\%), after which the fuel nozzle number starts to fall again. For the E3 engine model combustor, however, the number of fuel nozzles is not affected until the steam mass fraction reaches $20 \%$. As the fuel nozzle is connected to the swirlers that are installed in the dome of the burner, its amount is influenced by the dimensional restriction of both the liner and the swirler. When steam is added to the air, the relative change in the component design differs for these two model combustors, which results in the different characteristics of the fuel nozzle number variation for these two model combustors. This is another instance where multiple 
physical and chemical processes should be taken into account during combustor design with the addition of steam.

\section{Steam effect on combustor performance}

Analysis and evaluation of the combustor performance is also an important step during the conceptual design stage. Unlike the design calculation described in the previous section, the geometric size of the combustor components and the power setting conditions will be kept the same as those for the reference dry air design conditions. Thus, only the performance changes caused by the addition of steam need be studied.

The pressure loss coefficients for both the diffuser and the burner are fixed as both the configuration and dimensions of the combustors do not vary. The flow rates for different zones in the burner are calculated based on the corresponding swirler and air jet hole areas. When analyzing the combustor performance in the preliminary stage, many empirical and semi-empirical models are widely used for calculating the general parameters such as efficiency and NOx emissions. However, as a 1D flow field model is established in this paper, more detailed combustor performance information for different zones could be calculated based on the flow equations.
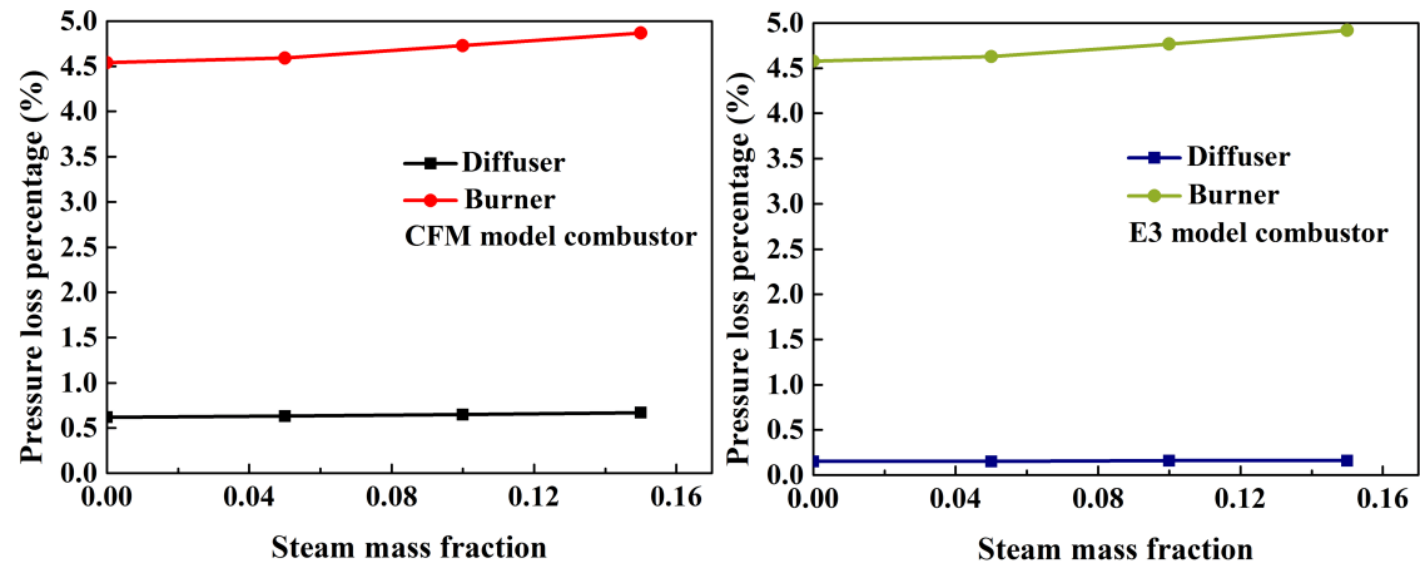

Fig. 3. Pressure loss percentage vs steam mass fraction. 
Fig. 3- 7 shows the change in the combustor performance for these two model combustors at different steam mass fractions. In Fig. 3, as the steam mass fraction increases, the total pressure loss percentage of the burner increases while the diffuser value is basically held constant. For CFM model, when the steam mass fraction reaches to $15 \%$, the pressure loss percentage becomes $4.87 \%$. So the relative change of this parameter for CFM combustor is $7.2 \%$. Meanwhile, in E3 combustor, the relative change of this parameter is about 7.4\%. Based on the definition of the pressure loss coefficient, the burner pressure loss is determined from the diffuser outlet dynamic pressure and the total pressure. Therefore, in this model, the steam chemical effect on the pressure loss is neglected in the calculation and these two parameters are altered due to the change in the gas properties with the addition of steam in the diffuser.
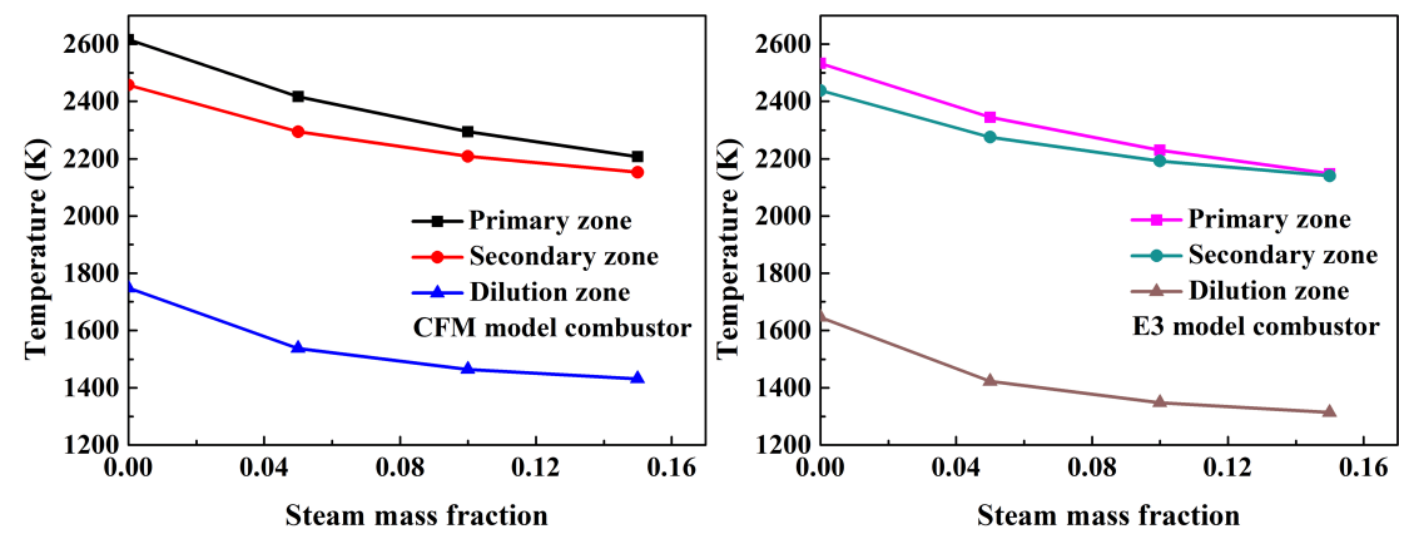

Fig. 4. Temperature at different zones vs steam mass fraction.

As shown in Fig. 4, the temperature in all of the zones is reduced when steam is injected into the combustor. In addition, the temperature reduction rate becomes smaller when the steam content is already high. Thus adding steam is not an economical way of reducing the combustor temperature if the steam mass fraction is already high. In CFM model, as steam mass fraction increases to $15 \%$, the outlet temperature of primary zone decreases $396.3 \mathrm{~K}$ while the secondary zone exit temperature reduces $291.3 \mathrm{~K}$. For E3 model, the outlet temperature for both the primary zone and the secondary zone are almost the same. It also reflects that the hot reactive zones are more sensitive to the addition of steam. Due to the 
total air flow rate and the combustor configuration being kept the same, the air distribution for different zones changes little, as shown in Fig. 5.
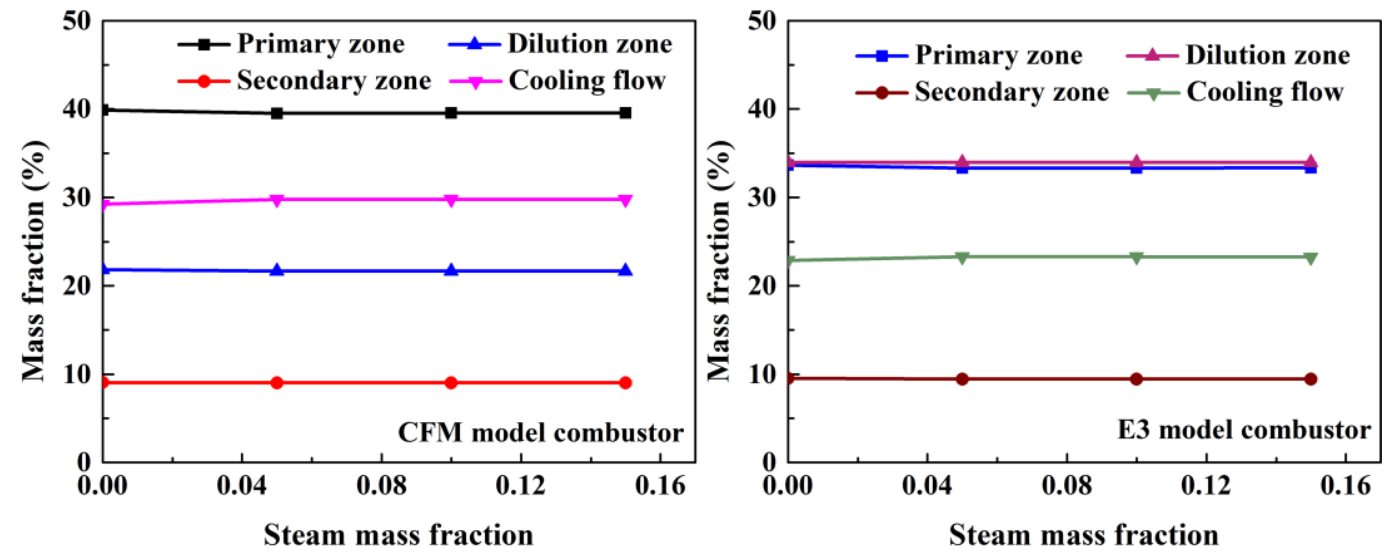

Fig. 5. Air distribution at different zones vs steam mass fraction.

Since the equivalence ratio is defined according to the dry air content in the mixture, it increases linearly with the steam mass fraction, as shown in Fig. 6. However, it should be noted that the equivalence ratio here is merely used as the measure of the air/fuel ratio, not as an indicator of the real temperature. As the steam mass fraction can reach a value as high as $15 \%$, the equivalence ratio in the secondary zone is nearly equal to the stoichiometric ratio. The high flame temperature under the stoichiometric ratio would partially offset the heat release reduction caused by the addition of steam. This partial heat compensation in the secondary zone is illustrated in Fig. 4, which shows that the outlet temperature of the secondary zone approaches that of the primary zone when the steam mass fraction reaches $15 \%$. 

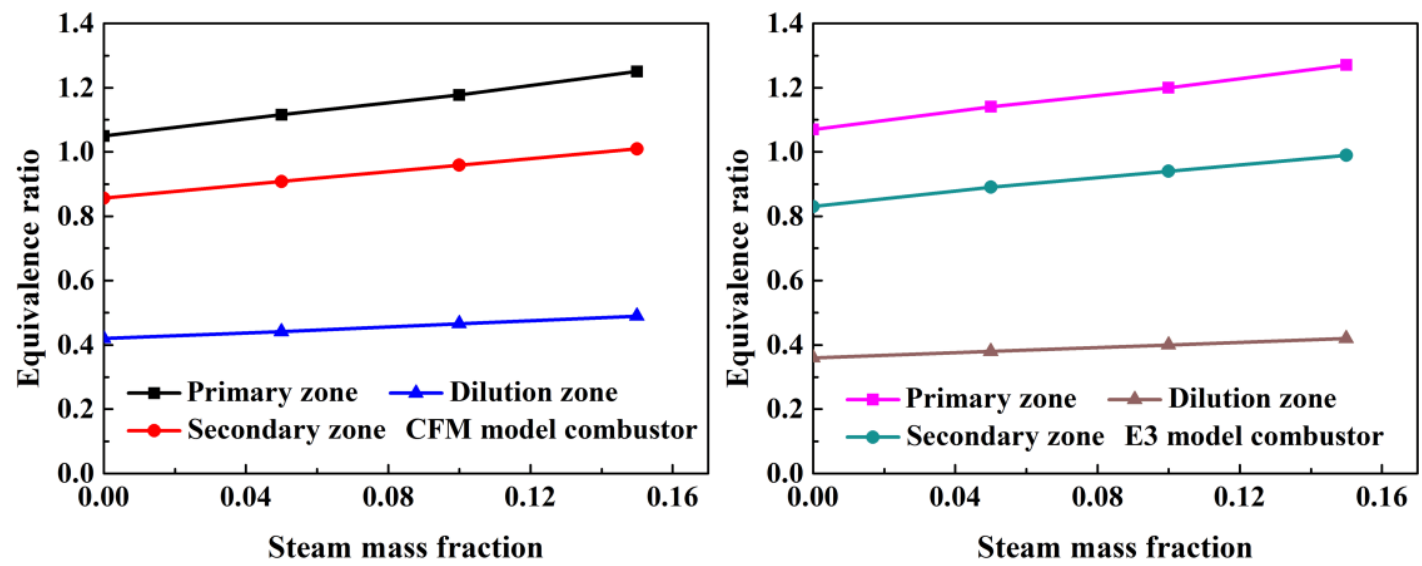

Fig. 6 Equivalence ratio at different zones vs steam mass fraction.

Generally, to guarantee that the flow field in the turbine will not influence the upstream flow in the combustor, the combustor outlet flow is usually designed to be in the choked state. As shown in Fig. 7, for a given total flow rate, if steam is mixed with the air in front of the diffuser, the combustor outlet Mach number will be decreased, leading to the outflow being unchoked. Since the flow area, the total pressure and temperature and the mass flow rate are fixed, it can be seen from Eq. (12) that steam addition influences the Mach number primarily as a result of changing the gas constant and the isentropic coefficient. As the density becomes larger as a result of the temperature falling at the outlet, the velocity is reduced to maintain a fixed outflow rate. Thus, the Mach number will not reach 1 unless the outlet area of the transition duct is designed to be varied when steam is added. 

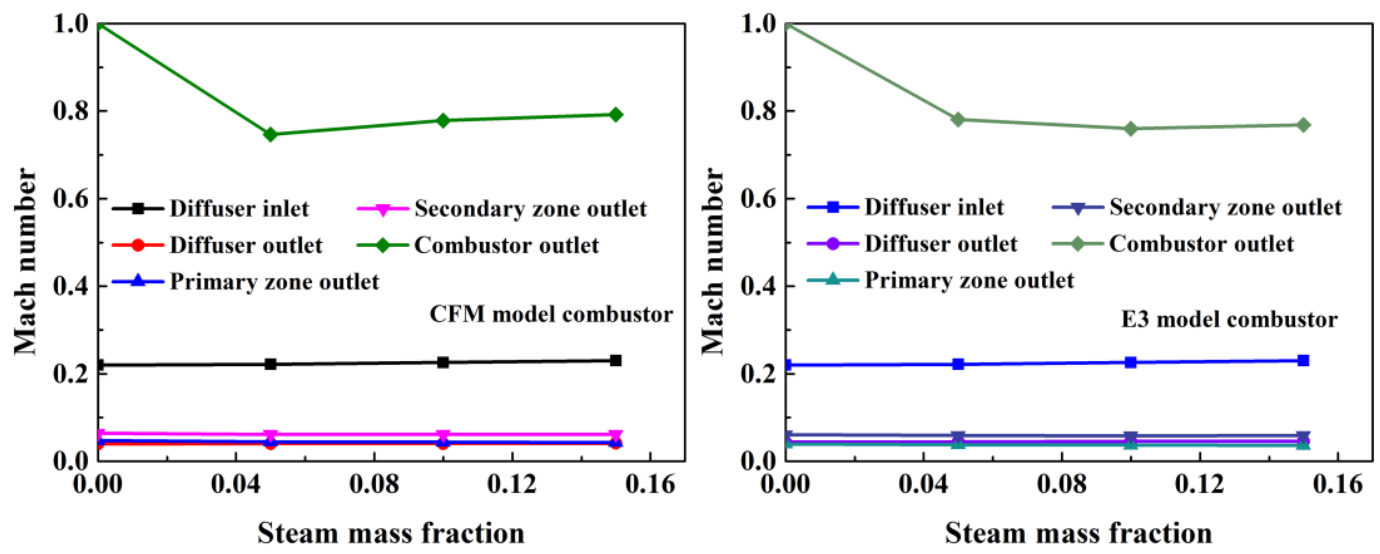

Fig. 7 Mach number at different zones vs steam mass fraction.

\section{Conclusion}

A combustor design procedure which takes the steam injection into account was established and validated for studying the effect of steam addition on the combustor design and performance at the conceptual stage.

The results show both the height and the length for different components in the combustor should be designed larger. Comparison of the relative change of the design dimension illustrates that the dimension variation extent is smallest for the diffuser where no combustion exists while for components which are in the drastic combustion environment like the primary zone, the dimension change is remarkable even not so much steam is added. The demand of the amount of air jet holes at the secondary zone would be reduced while the dilution zone needs more air jet holes when steam is injected. More specifically, the height of the combustor casing needs to be increased nearly $10 \%$ if $20 \%$ of steam in the inlet mixture is added.

Furthermore, adding steam could reduce the temperature in the burner. As the steam mass fraction increases, the outlet temperature of the secondary zone approaches that of the primary zone due to the heat compensation effect caused by higher equivalence ratio in the secondary zone. Other combustor 
performance, like the total pressure loss percent and the combustor outlet Mach number, would be slightly deteriorated with steam addition.

\section{Funding}

China Scholarship Council is gratefully acknowledged for the grant to R. Xue. This work has been supported by the National Natural Science Foundation of China (Grant No. 51576166).

\section{Declaration of conflicting interests}

The authors declare that there is no conflict of interest.

\section{References}

[1] V. Babkin and A. V'yun, Effect of water vapor on the normal burning velocity of a methane-air mixture at high pressures, Combust. Explo. Shock. 7(3) (1971) 339-341.

[2] E.V. Gurentsov, O.G. Divakov and A.V. Eremin, Ignition of multicomponent hydrocarbon/air mixtures behind shock waves, High Temp 40(3) (2002) 379-386.

[3] D.J. Hwang, J.W. Choi, J. Park, et al., Numerical study on flame structure and $\mathrm{NO}$ formation in $\mathrm{CH}_{4}-$ $\mathrm{O}_{2}-\mathrm{N}_{2}$ counterflow diffusion flame diluted with $\mathrm{H}_{2} \mathrm{O}$, Int. J. Energy. Res. 28 (2004) 1255-1267.

[4] A. Mazas, B. Fiorina, D. Lacoste, et al., Effects of water vapor addition on the laminar burning velocity of oxygen-enriched methane flames, Combust Flame 158(12) (2011) 2428-2440.

[5] S. Göke, M. Füri, G. Bourque, et al., Influence of steam dilution on the combustion of natural gas and hydrogen in premixed and rich-quench-lean combustors, Fuel Process Technol 107 (2012) 14-22.

[6] D.L. Daggett, Water misting and injection of commercial aircraft engines to reduce airport NOx, NASA Contractor Report, Report no.212957, March 2004. Ohio: NASA's Glenn Research Center. 
[7] V. Balepin, C. Ossello and C. Snyder, NOx emission reduction through water injection in Commercial Jets through water injection, NASA Contractor Report, Report no. 211978, October 2002. Ohio: NASA's Glenn Research Center.

[8] E. Benini, S. Pandolfo and S. Zoppellari, Reduction of NO emissions in a turbojet combustor by direct water/steam injection: Numerical and experimental assessment, Appl. Therm. Eng. 29(17) (2009) 35063510.

[9] S.J. Zhang, J.L. Chi, Y.H. Xiao, Performance analysis of a partial oxidation steam injected gas turbine cycle, Appl. Therm. Eng. 91(2015) 622-629.

[10] G. Heyen, B. Kalitventzeff, A comparison of advanced thermal cycles suitable for upgrading existing power plant, Appl. Therm. Eng. 19 (1999) 227-237.

[11] A.H. Mamaghani, B. Najafi, A. Shirazi, F. Rinaldi, Exergetic, economic, and environmental evaluations and multi-objective optimization of a combined molten carbonate fuel cell-gas turbine system, Appl. Therm. Eng. 77 (2015) 1-11.

[12] Carmona, J.. Gas turbine evaporative cooling evaluation for Lagos-Nigeria, Applied Thermal Engineering, 89 (2015) 262-269.

[13] F. N.M. Elwekeel, A. M.M. Abdala, Effect of mist cooling technique on exergy and energy analysis of steam injected gas turbine cycle, Applied Thermal Engineering, 98 (2016) 298-309.

[14] Timothy C. Lieuwen and Vigor Yang, Gas Turbine Emissions, London: Cambridge University Press, 2013, p.3.

[15] A.M. Mellor, Design of modern turbine combustors, London:Academic Press, 1990.

[16] Lefebvre and H. Arthur, Gas turbine combustion, 3rd ed. Philadelphia: Taylor\& Francis, 1999.

[17] B.S. Mohammad and S.M. Jeng, Design procedures and a developed computer code for preliminary single annular combustor design. In: $45^{\text {th }}$ AIAA/ASME/SAE/ASEE Joint Propulsion Conference \& Exhibit, Denver, Colorado, 2-5 August, paper no. AIAA 2009-5208. New York: ASME. 
[18] J.D. Mattingly, W.H. Heiser and D.T. Pratt, Aircraft Engine Design. 2nd ed. Reston: American Institute of Aeronautics and Astronautics, 2002, p. 235.

[19] O.L. Gülder, Flame temperature estimation of conventional and future jet fuels, J. Eng. Gas Turb Power 108(2) (1986) 376-380.

[20] O.L. Gülder, Combustion gas properties: Part III—prediction of the thermodynamic properties of combustion gases of aviation and diesel fuels, J. Eng. Gas Turb Power 110(1) (1988) 94-99.

[21] W. Dodds, Engine and aircraft Technologies to reduce emissions, In: UC Technology Transfer Symposium -Dreams of Flight. San Diego, USA, 1 March 2002.

[22] D. Burrus, P.E. Sabla and D.W. Bahr, Energy Efficient Engine (E3): component development and integration of single-annular combustor technology, Report, NASA Center, USA, October 1980.

[23] D. Burrus, P.E. Sabla and D.W. Bahr, et al., Energy Efficient Engine (E3): combustion system component technology performance, Report, NASA Center, USA, March 1984.

[24] J.R. Palmer, The TURBOMATCH scheme for gas turbine, Unpublished TURBOMATCH manual, September 2011.

[25] A.P. Vassilios. Gas turbine performance simulation, Unpublished lecture notes, September 2011. [26] M. Molnar and C.J.Marek, New reduced two-time step method for calculating combustion and emission rates of Jet-A and methane fuel with and without water injection. In: 38th Joint Propulsion Conference an d Exhibit cosponsored by the AIAA, ASME, SAE, and ASEE, Indiana,USA, 7-10 July, 2 002, paper no. NASA/TM 2004-213046. New York: ASME.

[27] D. Bucker, R. Span and W. Wagner, Thermodynamic property models for moist air and combustion gases, J Eng Gas Turb Power 125(1) (2003) 374-384.

\section{Appendix 1}

Flame temperature equation 
Based on the CEA results and the hydrocarbon fuel combustion performance, Gülder [19] proposed an expression to predict the adiabatic flame temperature of jet fuels. The equation is applicable in the following ranges: $0.3 \leq \phi \leq 1.6,0.1 \mathrm{MPa} \leq P \leq 7.5 \mathrm{MPa}, 275 \mathrm{~K} \leq T_{u} \leq 950 \mathrm{~K}$, and $0.8 \leq H / C \leq 2.5$.

$T_{a d}=A \sigma^{\alpha} \cdot \exp \left[\beta(\sigma+\lambda)^{2}\right] \cdot \pi^{x} \theta^{y} \psi^{z}$

where $x=a_{1}+b_{1} \sigma+c_{1} \sigma^{2}$

$$
\begin{aligned}
& y=a_{2}+b_{2} \sigma+c_{2} \sigma^{2} \\
& z=a_{3}+b_{3} \sigma+c_{3} \sigma^{2}
\end{aligned}
$$

$\pi$ is the dimensionless pressure $P / P_{0}$ where $P_{0}=0.1013 \mathrm{MPa}, \theta$ the dimensionless initial temperature $T / T_{0}$ where $T_{0}=300 \mathrm{~K}, \psi$ the $\mathrm{H} / \mathrm{C}$ atomic ratio, $\sigma=\phi$ for $\phi \leq 1$ where $\phi$ is the fuel-air equivalence ratio and $\sigma=\phi-0.7$ for $\phi>1$, and $A, \alpha, \beta, \lambda, a_{i}, b_{i}$ and $c_{i}$ are constants. In order to have an accurate prediction equation, four sets constants have been determined for the following ranges:

$0.3 \leq \phi \leq 1.0$ and $0.92 \leq \theta<2$

$0.3 \leq \phi \leq 1.0$ and $2 \leq \theta<3.2$

$1.0<\phi \leq 1.6$ and $0.92 \leq \theta<2$

$1.0<\phi \leq 1.6$ and $2 \leq \theta<3.2$

The values of constants for each range classification are listed in Table A.1

Table A.1 Constants for flame temperature estimation equation [19]

\begin{tabular}{ccccc}
\hline \multirow{2}{*}{ Constants } & \multicolumn{2}{c}{$0.3 \leq \phi \leq 1.0$} & \multicolumn{2}{c}{$1.0<\phi \leq 1.6$} \\
\cline { 2 - 4 } & $0.92 \leq \theta<2$ & $2 \leq \theta<3.2$ & $0.92 \leq \theta<2$ & $2 \leq \theta<3.2$ \\
\hline$A$ & 2361.7644 & 2315.752 & 916.8261 & 1246.1778 \\
$\alpha$ & 0.1157 & -0.0493 & 0.2885 & 0.3819 \\
$\beta$ & -0.9489 & -1.1141 & 0.1456 & 0.3479 \\
$\lambda$ & -1.0976 & -1.1807 & -3.2771 & -0.20365 \\
\hline
\end{tabular}




\begin{tabular}{lllll}
\hline$a_{1}$ & 0.0143 & 0.0106 & 0.0311 & 0.0361 \\
$b_{1}$ & -0.0553 & -0.045 & -0.0780 & -0.0850 \\
$c_{1}$ & 0.0526 & 0.0482 & 0.0497 & 0.0517 \\
$a_{2}$ & 0.3955 & 0.5688 & 0.0254 & 0.0097 \\
$b_{2}$ & -0.4417 & -0.5500 & 0.2602 & 0.5020 \\
$c_{2}$ & 0.1410 & 0.1319 & -0.1318 & -0.2471 \\
$a_{3}$ & 0.0052 & 0.0108 & 0.0042 & 0.0170 \\
$b_{3}$ & -0.1289 & -0.1291 & -0.1781 & -0.1894 \\
$c_{3}$ & 0.0827 & 0.0848 & 0.0980 & 0.1037 \\
\hline
\end{tabular}

Combustion gas properties equation

The equations [20] are applicable in the following ranges: $0 \leq \phi \leq 1.0,0.1 M P a \leq P \leq 7.5 M P a$, $300 K \leq T_{u} \leq 2500 K$, and $0.8 \leq H / C \leq 2.5$.

$\Omega_{k}=A S^{\alpha} \cdot \exp \left[\beta(\sigma+\lambda)^{2}\right] \cdot \pi^{x} \theta^{y} \psi^{z}$

For the temperature range $1500<T \leq 2500 K$

$\Omega_{1}=C_{p}$

$S=t=T / 1000$

$\theta=1.2358+1.03316 t-2.63325 t^{2}+3.77256 t^{3}-1.07368 t^{4}$

$x=a_{1}+b_{1} t+c_{1} t^{2}$

$y=a_{2}+b_{2} t+c_{2} t^{2}$

$z=a_{3}+b_{3} t+c_{3} \sigma t^{2}$

where $\sigma=\phi-0.45$

For the temperature range $400 \leq T \leq 1500 K$

$\Omega_{2}=C_{p}^{0.5}$ 


$$
\begin{aligned}
& S=\sigma=(\phi+0.5)^{2} \\
& x=a_{1}+b_{1} \sigma+c_{1} \sigma^{2} \\
& y=a_{2}+b_{2} \sigma+c_{2} \sigma^{2} \\
& z=a_{3}+b_{3} \sigma+c_{3} \sigma^{2}
\end{aligned}
$$

And $\theta$ is the dimensionless temperature, i.e.,

$\theta=T / 300$

For the temperature range $300 \leq T \leq 2500 K$

$\Omega_{3}=M W$

$S=\sigma=(\phi+1)^{2}$

$x, y, z$ and $\theta$ are the same as those given by equations (A1.15)- (A1.18).

$A, \alpha, \beta, \lambda, a_{i}, b_{i}$ and $c_{i}$ are constants, and their values are tabulated in Table A.2 for the two temperature ranges for both $C_{p}$ and $M W$.

Table A.2 Constants for combustion gas properties estimation equation [19]

\begin{tabular}{ccccc}
\hline & \multicolumn{2}{c}{ Specific Heat, $C_{p}$} & \multicolumn{2}{c}{ Molecular Weight, $M W$} \\
Const. & $400 \leq T \leq 1500$ & $1500<T \leq 2500$ & $300 \leq T \leq 1500$ & $1500<T \leq 2800$ \\
\hline$A$ & 0.99318 & 0.91153 & 30.0346 & 0.20501 \\
$\alpha$ & 0.006 & 1 & 0.00266 & -0.01537 \\
$\beta$ & 0.00098 & 0.02103 & -0.00121 & 0.000091 \\
$\lambda$ & -0.96083 & 1.8395 & -6.48722 & 232.731 \\
$a_{1}$ & 0 & -0.33224 & 0 & 0.000013 \\
$b_{1}$ & 0 & 0.3948 & 0 & 0.00112 \\
$c_{1}$ & 0 & -0.11764 & 0 & -0.000029 \\
$a_{2}$ & 0.06712 & 0.27269 & 0 & -0.00435 \\
$b_{2}$ & 0.01452 & -0.57967 & 0 & -0.00643 \\
\hline
\end{tabular}




\begin{tabular}{lcccc}
\hline$c_{2}$ & -0.002282 & 0.15654 & 0 & -0.00176 \\
$a_{3}$ & -0.00405 & 0.02401 & 0.02478 & 0.02502 \\
$b_{3}$ & 0.01853 & -0.53774 & -0.02762 & -0.02809 \\
$c_{3}$ & -0.00246 & 0.323 & 0.00219 & 0.00232 \\
\hline
\end{tabular}

\section{Appendix 2}

\section{Nomenclature}

A

area

$A_{1}$

diffuser inlet area

$A_{\text {Casing }}$

casing area

$A_{\text {Liner }}$

liner area

$A_{m}$

flat-wall diffuser outlet area

$A R$

combined flat-wall + dump diffuser area ratio

$A_{S W}$

swirler area

$c_{d}$

hole discharge coefficient

$C_{p, m i x}$

mixture gas heat capacity

$C_{p, i}$

ith component gas heat capacity

$d_{j}$

jet diameter

$d_{\text {orifice }}$

dilution hole diameter

$H_{\text {liner }}, \quad H_{-} L$

linear height

$K_{S W}$

swirler design parameter 
$R$

$r_{\text {hub }}$

$r_{\text {tip }}$

SW

$T_{\text {flame,wet }}$

$T_{\text {flame,dry }}$

$T_{\text {tot }}$

$w f f$

$w_{i}$

$Y_{\max }$

$\alpha_{S W}$

$\rho_{S W}$

$\eta_{t o t}$

$\eta_{D m}$

$\lambda$

$\gamma$ gas constant

swirler hub raidus

swirler tip raidus

swirl number

flame temperature with steam addition

flame temperature at dry air condition total temperature weight flow function ith component gas mass fraction maximum radial jet penetration swirler blade angle air density through swirler diffusion efficiency of the combined flat-wall + dump diffuser diffusion efficiency of the flat-wall diffuser steam to fuel mass ratio isentropic coefficient 
2016-05-12

\title{
Effect of steam addition on gas turbine combustor design and performance
}

\author{
Xue, Rui
}

Elsevier

Rui Xue, Chunbo Hu, Vishal Sethi, Theoklis Nikolaidis, Pericle Pilidis, Effect of steam addition on gas turbine combustor design and performance, Applied Thermal Engineering, Volume 104, 5 July 2016, Pages 249-257

http://dx.doi.org/10.1016/j.applthermaleng.2016.05.019.

Downloaded from Cranfield Library Services E-Repository 